\title{
Le regioni italiane non hanno governatori, ma presidenti
}

\section{Vittorio Coletti}

PUBBLICATO: 14 LUGLIO 2020

\section{Quesito:}

Alcuni lettori ci chiedono se sia opportuno usare, come i media fanno ormai da tempo, il termine governatore riferito ai presidenti delle regioni; una lettrice chiede anche quale sia la forma del femminile.

\section{Le regioni italiane non hanno governatori, ma presidenti}

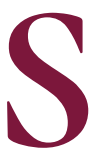

e lasciamo da parte per una prossima occasione la questione della morfologia femminile di governatore, a maggior ragione potremmo archiviare la proposta sulla sua pertinenza come titolo dei presidenti di regione in Italia rinviando a quanto abbiamo scritto (20/7/20r8) a proposito di premier. Come il premier inglese non è previsto, né nel nome né nei poteri e ruoli, dalla nostra costituzione, cosi i governatori non hanno posto nel nostro ordinamento. In Italia, l'unico a potersi fregiare di questo titolo è appunto il governatore della Banca d'Italia, come ha ricordato Antonio Patuelli. Con questo nome designano il loro massimo dirigente anche altre banche nazionali e gli inglesi lo usano pure per membri di qualche consiglio di amministrazione. In ogni caso basta un'occhiata a Wikipedia per controllare dove è in uso il corrispondente del nostro governatore e si fa presto a vedere che, in campo politico-istituzionale, questo titolo designa quasi sempre il capo di governo di uno stato inserito in una federazione, come negli USA.

La parola è ripresa proprio dagli Stati Uniti, ma non è ovviamente un anglismo. Se non vogliamo retrocedere sino a ricordare il celebre e infelice "governatore della Giudea", Ponzio Pilato, delle antiche traduzioni della Bibbia, potremmo anche fermarci ai governatori dei territori africani ai tempi dell'Impero fascista, tanto per citare un precedente non proprio onorevole di questo titolo. Abusivamente i giornali lo hanno attribuito ai presidenti delle nostre regioni, che in effetti tendono sempre più a fare da governatori, ma non lo sono, anche perché non è uno stato confederato con altri quello di cui presiedono il governo.

Posta dunque l'improprietà istituzionale del nome, come quella di premier, frutto dell'americomania dei nostri media, riflettiamo un po' sulla parola, visto che è pienamente nostra, discesa dal latino gubernatorem, e già attestata in italiano dal Duecento. In latino il significato di base era quello di chi regge il governo di una nave, il timoniere che la governa. Ma già in latino si era sviluppato quello esteso di 'guidatore, reggitore', anche con responsabilità politiche. Il TLIO registra quasi tutti questi valori dal tardo XIII secolo, dal "governatore de la nave" citato nei Fatti di Cesare ai "Nove governatori e difenditori del chomune e del popolo di Siena" di un documento senese della stessa epoca, passando attraverso valenze più generiche di guida spirituale o politica.

La prima edizione del Vocabolario della Crusca, che categorizza la parola anche come aggettivo, restringe ormai il significato al ruolo di capo politico. Come si può vedere consultando la minuziosa voce del GDLI, la parola è passata dal suggerire un ruolo morale a indicarne uno via via più organizzativo e infine decisamente istituzionale (sembra soprattutto dal XVI secolo). Anche il femminile governatrice, sia pure con un ventaglio più ristretto di significati e senza responsabilità politiche, circola dal Duecento. 
Dunque governatore è parola antica, pienamente italiana. Ma non è corretto utilizzarla per designare i presidenti delle regioni in Italia, anche se ha nella sua lunga storia precedenti di stampo istituzionale, ai più diversi livelli e in differenti àmbiti (civile, religioso, amministrativo, militare ecc.). Il valore che le si attribuisce oggi è, come si diceva, quello che assimila il ruolo denominato a quello del capo del governo di uno stato aggregato ad altri in una federazione governata da un presidente, come negli USA. Questa caratteristica non si dà in Italia, né nell'ordinamento statuale né in quelli regionali. Ma è vero che l'uso e l'abuso della parola in parte rispecchiano una realtà politica e istituzionale in evoluzione (dei presidenti di regione verso il ruolo e i poteri del governatore americano, delle regioni verso una specie di stato) e il desiderio o l'ambizione non nascosti dei capi delle giunte regionali, specie dopo che il sistema elettorale li ha fortemente messi in rilievo. Usando allora governatore, i giornali e la gente avallano un (modesto) abuso istituzionale e favoriscono un evidente progetto politico. Chi non approva l'uno e non condivide l'altro, farebbe bene a starci attento a usare la parola, anche se temo che ormai sia tardi per far retrocedere certi presidenti di regione dal rango superiore dei governatori a quello di semplici presidenti. Ancora piu difficile indurre i media alla precisione invece che allo stereotipo. L'archivio della "Repubblica" dal 1984 a oggi registra più di IIo mila attestazioni di governatore. Orbene, fino al 2000 erano solo ro mila, più di 3 mila dei quali erano quelli, autentici, della Banca d'Italia e (circa 30o) degli stati americani. Quindi meno di 7 mila. Ma i 7 mila governatori abusivi in 16 anni sono diventati circa 94 mila in 20: a tanto ammonta il loro numero sottraendo gli oltre 5 mila legittimi, riferiti alla massima autorità della nostra Banca centrale o a quella della BCE e (circa 60o) e a capi di governo degli stati confederati in USA: una crescita, direbbero subito i giornali, davvero "esponenziale"!

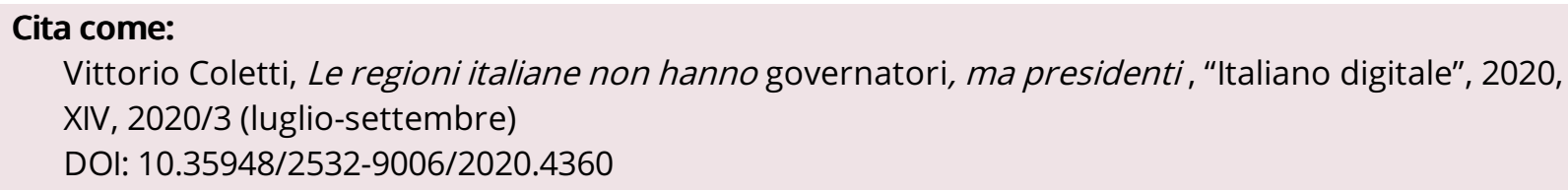

